\title{
Solar energy's path towards competitiveness
}

\author{
Progress in photovoltaic technology could soon mean grid parity for solar electricity. In this issue we \\ highlight scientific as well as science-policy strategies aimed towards achieving this goal.
}

Ever since Daryl Chapin, Calvin Fuller and Gerald Pearson developed the first practical solar cells ${ }^{1}$ at Bell Laboratories in 1954, solar power has been hailed as a key clean-energy technology. Yet we have still not reached full grid parity - where electricity generation is commercially competitive with sources such as oil or coal. The requirements for grid parity vary widely, depending on local factors such as the annual number of Sun hours as well as the local costs of competing technologies. For example, although solar-energy generation in Arizona is already as cheap as 10 cents per kilowatt hour (ref. 2), costs in Europe can be almost twice that amount. To achieve full grid parity the US Department of Energy (DOE) estimates production costs should not be higher than 6 cents per kilowatt hour.

In an area where almost every $1 \%$ increase in solar-conversion efficiency is celebrated, it may seem that such a steep price reduction could be impossible to achieve. However, a significant amount of the costs arise from fabrication and installation of the solar panels, and there is a clear benefit of scale. Owing to the increasing popularity of solar electricity, costs have already come down by about a factor of four over the past decade.

To progress even further, a wider approach needs to be taken to reduce costs by dealing with issues ranging from solarconversion efficiency to the permitting costs for new solar-panel installations. To this end, the DOE has set up an ambitious programme, SunShot, whose aim is to bring down the cost of solar energy to 6 cents per kilowatt hour by 2020. As the programme's director, R. Ramesh, explains in an Interview ${ }^{3}$ on page 178 of this issue, the approach taken by the programme is unique in several ways.

First, SunShot tackles the problem from the supply front rather than the consumer front. If prices can be made competitive through technology, the argument is that consumers will not need financial incentives to have roof-top installations. This view is particularly compelling, because the subsidies are spiralling as solar installations become more popular - Germany at present spends about eight billion euros every year on subsidizing solar feed-in tariffs. Schemes that advance the competitiveness through technology not only save money used for such subsidies, but also create the necessary know-how on a crucial future technology.

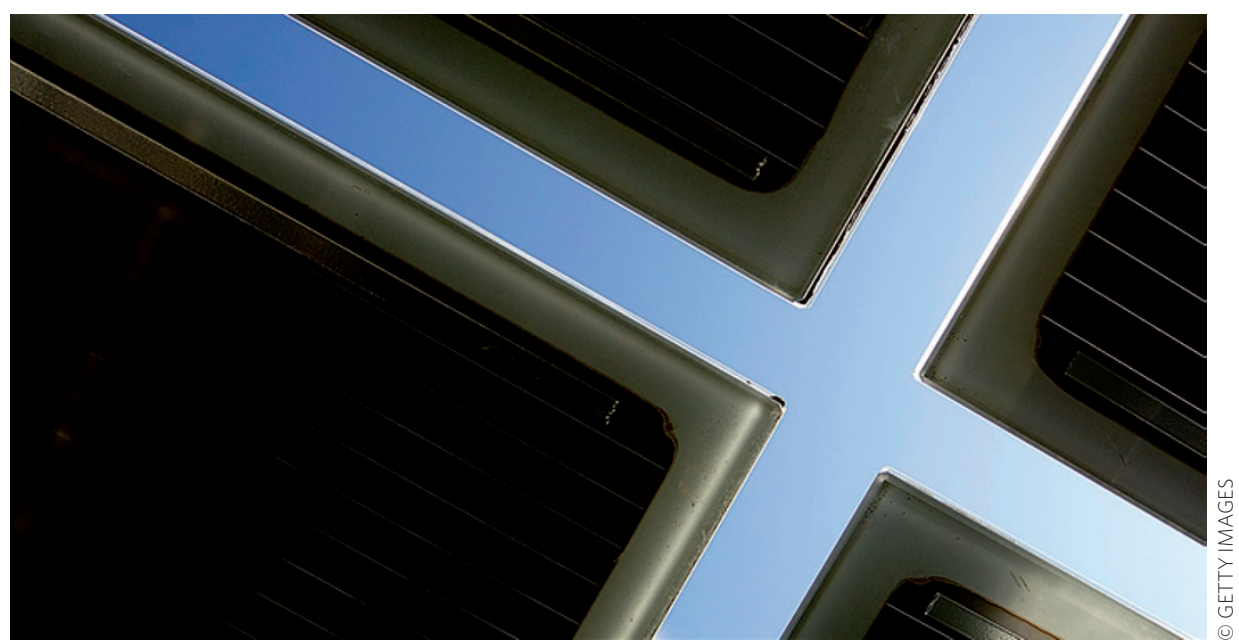

What is also compelling about the SunShot programme in particular is that it looks at costs across all areas, and in doing so cuts across established DOE hierarchies.

One of SunShot's major activities, however, is to increase the efficiency of solar cells, where there is still a lot of ground to be gained. As Albert Polman and Harry Atwater write in their Commentary ${ }^{4}$ on page 174 of this issue, even though record efficiencies have now reached $28.3 \%$ for GaAs single-junction solar cells, efficiencies of typical commercial installations remain in the teens. None are even close to the fundamental thermodynamic limit, but they are close to the Shockley-Queisser limit, which considers limits of efficiency of conventional semiconductors. Although the Shockley-Queisser limit is often seen as insurmountable for conventional solar cells, Polman and Atwater argue that this needn't be the case if advanced designs are used. For these the thermodynamic maximum is the only limit. The idea is to modulate the light flow within a solar cell in a way that removes some of the conventional loss factors such as entropy losses that arise when, for example, the directed light beam from the Sun scatters in all directions within the cell.

The success of these new design considerations for solar cells is already apparent from recent results. The $28.3 \%$ record efficiency for solar cells is not obtained with a thick semiconductor cell that merely maximizes light absorption. Instead, it is from a thin GaAs film with a metallic mirror on the back. The reflection from the back improves the light management inside the cell and enables efficiencies beyond bulk materials ${ }^{5}$. Further design improvements as outlined in the Commentary could boost efficiencies even further.

Enhancements in solar-cell performance suggest that grid parity for solar power won't be just something dreamed up by industry representatives. Supporting basic research, as SunShot does, is a way of securing technological know-how. At the same time, renewable solar energy cannot be seen as an isolated technology. Wind and other clean technologies need to be developed in parallel. The storage of the energy produced in the form of fuel or in batteries is another major issue, tackled for example at the DOE through the so-called energy-innovation hubs. Furthermore, it should be clear that renewable energy also requires billions of dollars in investments in smart power grids that are able to cope with regional variations in energy output. But as the contributions to this focus issue emphasize, in the long term this could be achieved in a manner that is commercially competitive as well as being best for the environment.

\footnotetext{
References

1. Chapin, D. M., Fuller, C. S. \& Pearson, G. L. J. Appl. Phys. 25, 676-677 (1954)

2. Brankera, K., Pathaka, M. J. M. \& Pearcea, J. M. Renew. Sust. Energ. Rev. 15, 4470-4482 (2011).

. Nature Mater. 11, 178-179 (2012).

4. Polman, A. \& Atwater, H. Nature Mater. 11, 174-177 (2012)

5. Miller, O. D., Yablonovitch, E. \& Kurtz, S. R. Preprint at http://arxiv.org/abs/1106.1603 (2011).
} 